\title{
Synthesis of Biocompatible Surfaces by Nanotechnology Methods
}

\author{
A. P. Alekhin ${ }^{a *}$, G. M. Boleiko ${ }^{a}$, S. A. Gudkova ${ }^{a}$, A. M. Markeev ${ }^{a}$, \\ A. A. Sigarev ${ }^{a}$, V. F. Toknova ${ }^{a}$, A. G. Kirilenko ${ }^{b}$, R. V. Lapshin ${ }^{b}$, \\ E. N. Kozlov' and D. V. Tetyukhin ${ }^{c}$ \\ ${ }^{a}$ Moscow Institute of Physics and Technology (State University), Institutskii per. 9, Dolgoprudnyi, Moscow oblast, 141700 Russia \\ ${ }^{b}$ Lukin State Research Institute for Problems in Physics, Proezd 4806, 6, Zelenograd, Moscow, 103460 Russia \\ ${ }^{c}$ Conmet Ltd., ul. Onezhskaya 24/1, Moscow, 125413 Russia \\ *e-mail: alekhin@mail.mipt.ru \\ Received December 17, 2009; accepted June 9, 2010
}

\begin{abstract}
The modification of the surface of low-density polyethylene (LDPE) and polyurethane (PU) by means of the pulsed ion-plasma deposition of nanostructural carbon coatings at $20-60^{\circ} \mathrm{C}$ has been studied. The effect of this low-temperature treatment on the biocompatibility of the LDPE and PU has been assessed. Optimum technological parameters for the formation of mosaic carbon nanostructures with a thickness of $0.3-15 \mathrm{~nm}$ and a cluster lateral size of $10-500 \mathrm{~nm}$ are determined. These structures give the polymer surface increased hemocompatible properties. The surface of samples was studied by methods of scanning electron microscopy, scanning probe microscopy, and Raman spectroscopy. The effect of the UV light of a krypton $\operatorname{lamp}(\lambda=123.6 \mathrm{~nm})$ and white synchrotron radiation on the surface of poly(methyl methacrylate) (PMMA) preliminarily treated in an oxygen-containing RF discharge plasma has been investigated by varying the duration of exposure (from several minutes to several dozen minutes) and the residual gas pressure (2 and $100 \mathrm{~Pa})$. This processing ensures the smoothing of the surface relief on micro- and nanoscale levels, which can improve the biocompatibility of the modified PMMA film surface. The principles of a two-stage technology for rendering the titanium (implant) surface biocompatible are developed. This technology consists of the chemical pretreatment of the surface for creating a microrelief ( $2-3 \mu \mathrm{m}$ roughness), followed by the deposition of a titanium oxide film with controlled composition $\left(\mathrm{TiO}_{2}\right)$ and thickness $(10-60 \mathrm{~nm})$. The influence of the mechanisms and technological parameters of the oxide film deposition on its composition, structure, uniformity (conformal coating of involved shapes), and biocompatibility of the modified surface have been studied.

DOI: $10.1134 / \mathrm{S} 1995078010090144$
\end{abstract}

\section{SYNTHESIS OF CARBON NANOCLUSTER STRUCTURES FOR OBTAINING HEMOCOMPATIBLE SURFACES}

In recent years, methods have been extensively developed for the synthesis of carbon nanostructures such as clusters, fullerenes, and nanotubes on the surface of various materials, making it possible to control their biomedical properties, in particular, hemocompatibility [1]. However, the lack of knowledge of the formation mechanisms of hemocompatible surfaces complicates the establishment of unique relationships between the parameters of nanostructural carbon coatings and their biomedical characteristics, which hinders the wide use of these coatings in practical implantology.

In this study, the surfaces of $60-\mu m$-thick low-density polyethylene (LDPE, Russian State Standard GOST 10354-82) and 150- $\mu \mathrm{m}$-thick polyurethane (PU, Vitur T-0533-90 grade), which are widely used in medicine, were modified by carbon nanoclusters. The modification of polymers was performed by the method of the pulsed ion-plasma deposition of carbon on an UVNIPA-1-001 setup as described previously $[2,3]$.

Attempts to use continuous carbon coatings on the surface of medical polymers did not give stable positive results. On the contrary, the formation of a carbon layer that consists of clusters with dimensions favoring the adsorption of useful blood protein molecules such as albumin and preventing the adsorption of harmful fibrinogen molecules showed a significant positive effect, which was manifested by the increasing thromboresistance of the modified polymer materials [4].

We propose a new scheme for obtaining hemocompatible surfaces which is based upon two experimental facts: (i) there were no proteins of blood plasma adsorption on a continuous carbon coating and (ii) the proteins exhibit selective adsorption on the sites of the polymer surface free of carbon, so is a correspondence between the dimensions of blood plasma proteins and those of carbon-free surface sites. Figure 1 schematically illustrates the mechanism of selective adsorption 


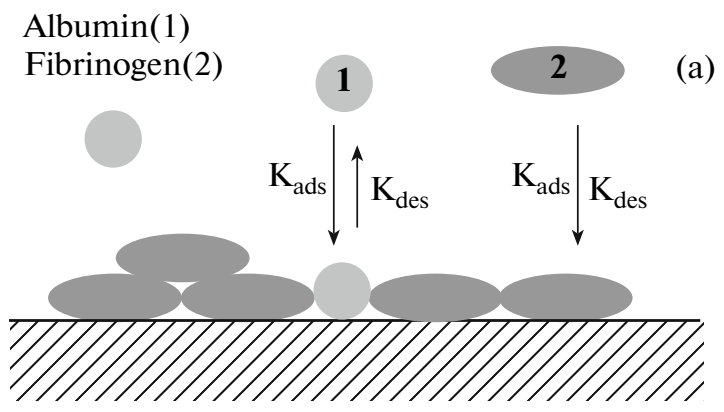

Carbon cluster(3)

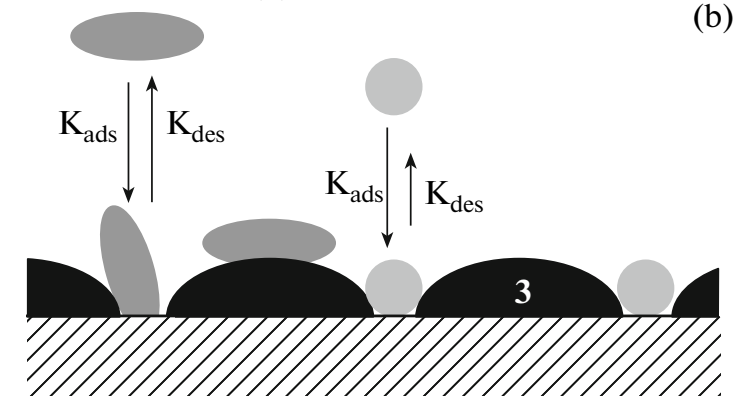

Fig. 1. Schematic diagram illustrating the adsorption-desorption of (1) albumin and (2) fibrinogen molecules on the (a) initial and (b) modified polymer surface containing carbon clusters (3). Arrows indicate the relative rate constants of adsorption $\left(K_{\mathrm{ads}}\right)$ and desorption $\left(K_{\mathrm{des}}\right)$ for albumin and fibrinogen.

of albumin molecules in competition with fibrinogen molecules.

As can be seen from Fig. 1a, both albumin and fibrinogen molecules adsorb on the initial polymer surface. Fibrinogen molecules, which are 4-5 times greater than albumin molecules $(\sim 50 \mathrm{~nm}$ against $\sim 9 \mathrm{~nm}$, respectively), are, for thermodynamic reasons, almost irreversibly adsorbed so that they stick to the substrate with their maximum surface area. In contrast, part of the modified surface (Fig. 1b) is occupied by carbon clusters so that fibrinogen molecules have no area to settle and stick, whereas significantly smaller albumin molecules can readily adsorb on carbon-free surface sites. Practical implementation of this adsorption scheme would improve the hemocompatibility of polymer surfaces and eliminate the formation of thrombuses.

In order to provide conditions for the selective (competitive) adsorption of albumin and fibrinogen molecules as depicted in Fig. 1, it is necessary to produce the nanostructurization of the substrate surface by carbon clusters so that the dimensions of open (adsorption-accessible) surface regions between the clusters are be on the order of several units to several dozen nanometers.

As is known, the ion-plasma deposition of nanostructural carbon coatings in a pulsed rather than continuous regime makes it possible to quite simply control the degree of carbon supersaturation $(\Delta g)$ in the gas phase and, hence, the mechanism of initial growth stages [5]. Indeed, as low $\Delta g$ values, the carbon film growth may proceed via the layered or two-dimensional (2D) mechanism of nucleation and growth. The probability of this process is characterized by the isobaric-isothermal potential $\Delta G_{2} \sim 1 / \Delta g$. As the $\Delta g$ value increases, the mechanism can change from $2 \mathrm{D}$ to $3 \mathrm{D}$, in which case $\Delta G_{3} \sim 1 / \Delta g^{2}$ (power dependence) and the conditions are more nonequilibrium. This circumstance implies a greater possibility that the carbon-coated surface morphology will be influenced by the varying conditions of the technological process. In addition, the pulsed regime facilitates the removal of heat from the substrate surface, since the period of time between pulses is an order of magnitude greater (as characterized by the off/on ratio) than the pulse duration. The parameters of this technological process can be optimized by studying the surface morphology and introducing changes in the process so as to obtain the desired surface relief.

Figure 2 schematically illustrates the dynamics of film nucleation and growth according to the VolmerWeber (island growth) mechanism. At the stage of car- (a)

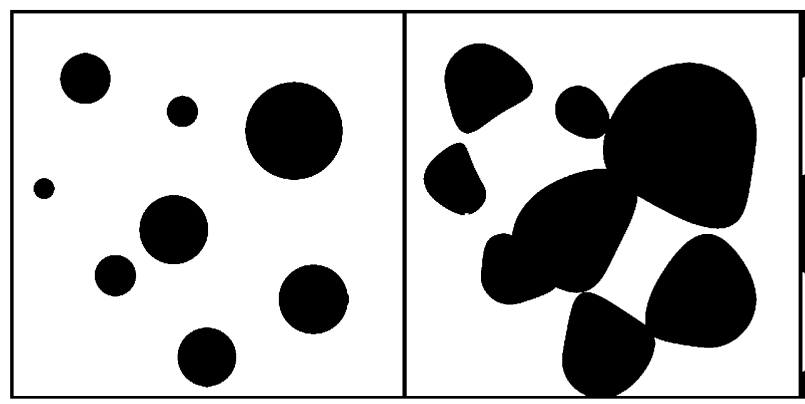

(c)

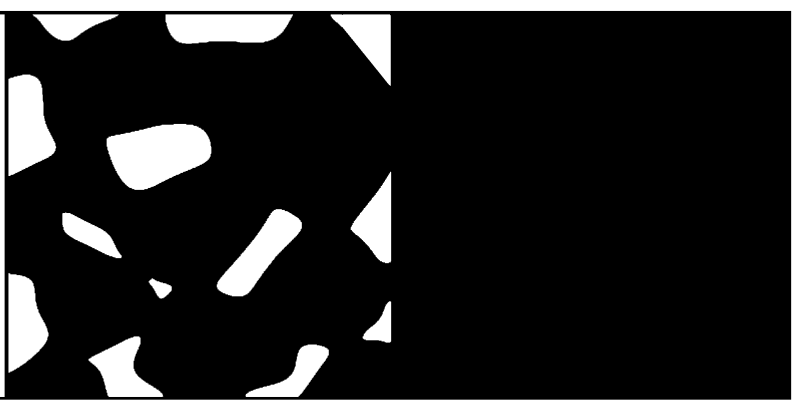

Fig. 2. Schematic diagram of the island nucleation and film growth mechanism: (a) nucleation and growth of carbon clusters without mutual interactions; (b) lateral growth and island formation; (c) coalesce of islands at a sufficiently large surface coverage and the formation of a network with electrically continuous structure capable of conducting electric current (percolation threshold); (d) formation of a continuous film. 
bon coating formation, it is necessary to determine the so-called percolation threshold (see Fig. 2c), whereby a carbon network that forms an electrically continuous structure capable of conducting electric current is formed, typically when the substrate is covered up to $70-80 \%$. Why is determining the percolation threshold so important? Because this point at the stage of carbon deposition corresponds to the formation of a mosaic carbon nanostructure with cluster dimensions in a nanometer range. This situation leads to a change in the physicochemical and biomedical properties, thus making it possible to control the hemocompatibility of the carbon-modified surface $[7,8]$. It is highly probable that the percolation threshold determines the final stage of formation of a hemocompatible mosaic cluster structure on the substrate surface. In this study, the percolation threshold was determined as a function of the number $N$ and the repetition frequency $f$ of pulses of the carbon plasma generator. The thickness of the deposited carbon coating varied within $0.3-$ $15 \mathrm{~nm}$. The proposed technology was experimentally implemented and patented [6].

\section{DETERMINING THE TECHNOLOGICAL PARAMETERS AND PHYSICAL AND BIOMEDICAL PROPERTIES OF PLASMA-DEPOSITED CARBON NANOSTRUCTURES}

We have experimentally determined the optimum technological parameters for the process of LDPE and PU modification by carbon clusters to reach a percolation threshold as the pulse repetition frequency $f=$ $1 \mathrm{~Hz}$ and their number $N=50$, which corresponded to an effective carbon coating thickness of $\sim 7.5 \mathrm{~nm}$. The surface morphology of samples was studied by scanning electron microscopy (SEM) and scanning probe microscopy (SPM).

The SEM measurements were performed on a Camscan 4 (Cambridge Instruments) microscope with a typical magnification of $\times 1000-5000$, which corresponds to the size of visible fields on a level of several tens of microns. By studying the characteristic features of morphology, it is possible to evaluate the optimum technological parameters, introduce the necessary corrections, and obtain the surface relief necessary for further research. It was established that the relief of modified polymer surfaces was significantly dependent on the number $N$ of carbon plasma pulses and their repetition frequency $f$. The dynamics of variation of the surface relief exhibited the following trends. At a small amount of the deposited material $(N=2-10)$, the necessary surface morphology (corresponding to Fig. 2c) is not formed. In this case, the carbon-modified polymer surface has a globular structure, i.e., exhibits separate clusters with dimensions within 100-200 nm. Large values of the pulse repetition frequency and number $(f \geq 10 \mathrm{~Hz}, N \geq 100)$ corresponded to the formation of structures representing either fibrils (3000-4000 nm long) or continuous chains. The most favorable regimes were those with $f=$ $0.3-1.0 \mathrm{~Hz}$ and $N=30-50$.

Direct evidence for the formation of a carbon cluster structure on the LDPE surface was provided by the results of SPM investigations in air at room temperature. These measurements were performed on a Solver ${ }^{\mathrm{TM}}$ Pro M (NT-MDT Company) instrument operating in a tapping mode with 2D and 3D imaging. The cantilever had an elasticity coefficient of about $20 \mathrm{~N} / \mathrm{m}$ and a resonance frequency of $131.851 \mathrm{kHz}$; the point probe had a tip radius of several nanometers. The minimum spatial resolution of the microscope, as evaluated by the size of the minimum visible elements of the sample surface, was about $10 \mathrm{~nm}$.

Figures 3 and 4 present typical 2D images obtained by an SPM examination of LDPE and PU modified at various repetition frequencies $(f=0.1-1.0 \mathrm{~Hz})$ and numbers $(N=30-50)$ of carbon plasma pulses. As the pulse repetition frequency was increased from 0.1 to $1.0 \mathrm{~Hz}$ and/or their number was increased from 2 to 50 , the size of the deposited carbon clusters or their aggregates, as well as the degree of surface coverage by carbon, increased to $70-80 \%$. This led to the formation of a mosaic carbon network with an electrically conducting structure.

Thus, based on our results, it was concluded that the optimum pulse repetition frequency and carbon deposition velocity for the formation of the desired cluster structure on the polymer surface are $0.3-1 \mathrm{~Hz}$ and $0.1-0.2 \mathrm{~nm} / \mathrm{s}$, respectively.

Additional information on the structure of modified carbon coatings on polymer substrates was obtained by mathematically processing their Raman spectra [9]. An analysis of parameters such as the Raman shift and the heights and widths of model spectrum components (Fig. 5), which were determined using the results of Tamba et al. [10], allowed us to make the following conclusions concerning the structure of layers formed on polymer substrates. It was evident that both $s p^{2}$ and $s p^{3}$ hybridization is present in carbon deposits. According to the general principles of thermodynamics, structural elements with the $s p^{2}$ type of hybridization form small-size clusters. Of all the possible clusters of this kind, the most probable are six-member rings, which can be either separate or connected into sets of several rings. These rings may possess angular misorientation and can be shaped like irregular hexagons. These clusters are bound by elements of the $s p^{3}$ hybridization and can be chaotically oriented relative to each other.

Medico-technical investigations were performed at the Research Institute of Transplantology and Artificial Organs (Ministry of Public Health of the Russian Federation, Moscow), which involved (i) an analysis of the thrombocyte adhesion with allowance for their morphological characteristics and (ii) a determination 
(a)
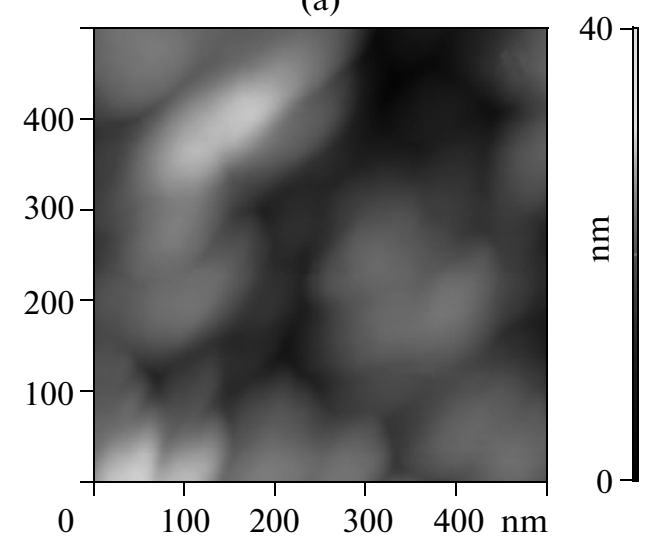

(b)
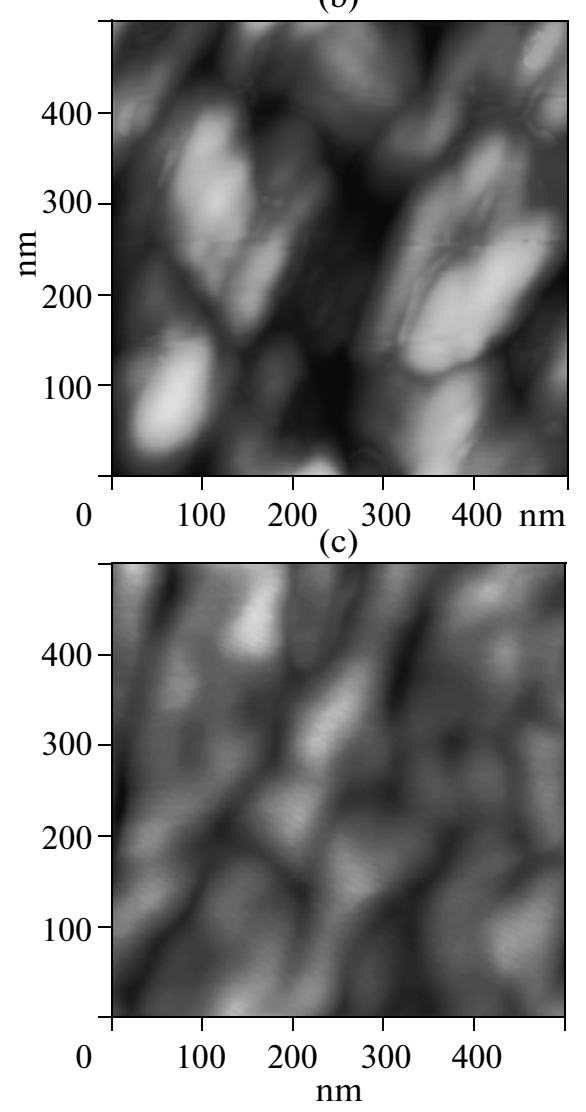

40
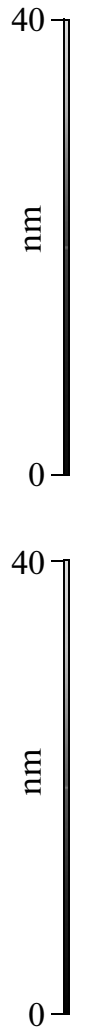

Fig. 3. 2D images obtained by SPM examination of LDPE surface modified by $N=30-50$ pulses of carbon plasma at a repetition frequency of $f=$ (a) 0.1 , (b) 0.3 , and (c) $1.0 \mathrm{~Hz}$.

of the degree of activation of the complement system based on the general hemolytic activity of the complement in human blood serum. The results showed (see table) that the proposed modification of the polymer surface by carbon leads to a decrease in the thrombocyte (platelet) adhesion and a drop in the rate constant $K_{\text {ind }}$ of induced activation of the complement system. These characteristic were calculated using the times of the half-lysis of sensitized goat erythrocytes by human blood serum before and after incubation (a)

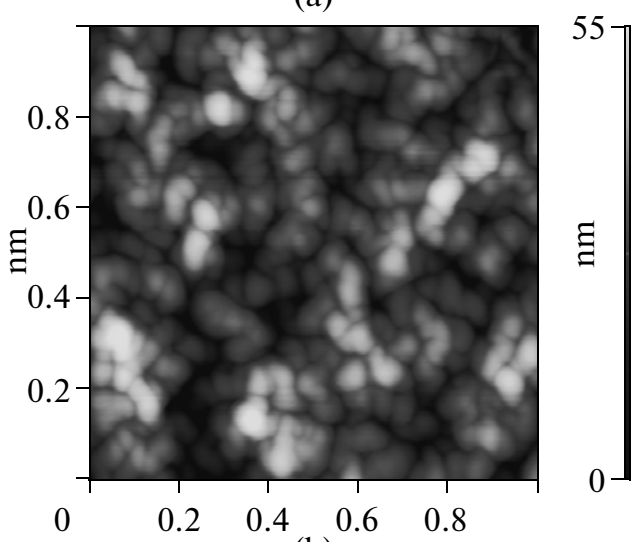

(b)
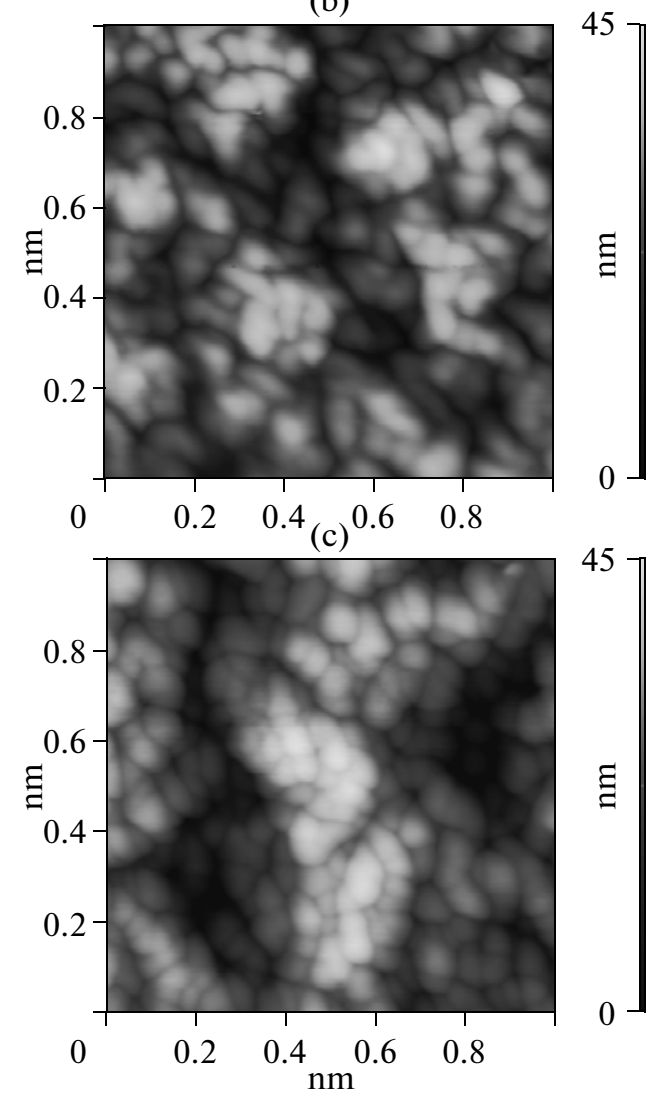

Fig. 4. 2D images obtained by a SPM examination of the PU surface modified by $N=30-50$ pulses of carbon plasma at a repetition frequency of $f=$ (a) 0.1 , (b) 0.3 , and (c) $1.0 \mathrm{~Hz}$.

with a sample. The surface is classified as hemocompatible, provided that its $K_{\text {ind }}$ does not exceed 1.5. It should be noted that the initial polymer surfaces had $K_{\text {ind }}=5.1$ and 5.5 for LDPE and PU, respectively. An analysis of data in the table shows that the proposed modification significantly improves the hemocompatibility of the polymer surface at an affective carbon film thickness of 5-12 $\mathrm{nm}$ and cluster dimensions within 50-120 nm. 


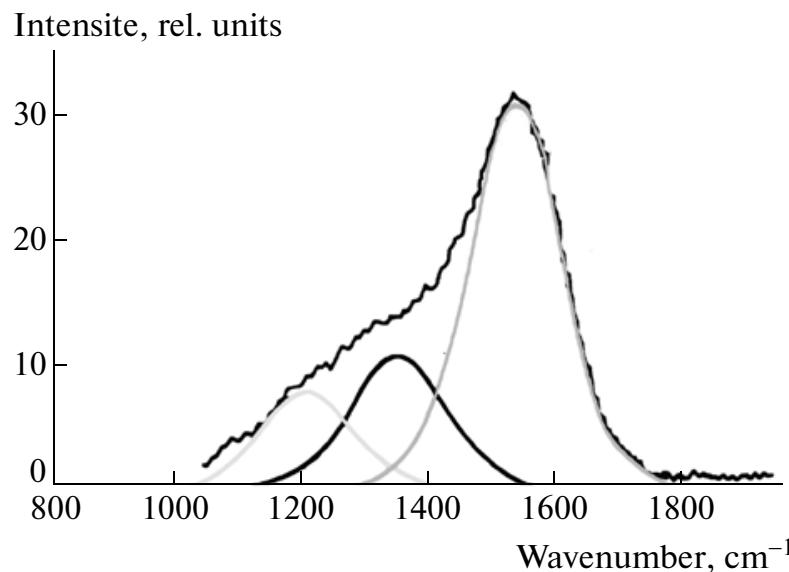

Fig. 5. Analysis of the Raman spectrum of a carbon coating showing general line envelope and its components corresponding to $s p^{2}$ hybridization, $s p^{3}$ hybridization, and misoriented states, respectively.

\section{NANOSTRUCTURAL MODIFICATION OF POLY(METHYL METHACRYLATE) SURFACE BY A COMBINATION OF PLASMACHEMICAL TREATMENT AND VACUUM ULTRAVIOLET IRRADIATION}

Poly(methyl methacrylate) (PMMA) is now widely used in practical transplantology as a base material for various implants [11].

\section{Plasmachemical Processing of PMMA Surface}

Previously, Vasilets et al. [12,13] showed that plasmachemical processing and vacuum ultraviolet (VUV) irradiation modify the properties of near-surface layers of medical polymers. The destruction of polymers and the formation of active chemical radicals and species under these conditions make it possible to control the biocompatibility of the polymers. In particular, the modification of the near-surface layers of a polymer leads to a change in its nanoroughness. In this context, we have studied the effect of plasmachemical treatment in an oxygen-containing medium at a small partial pressure $(\sim 2 \mathrm{~Pa})$ followed by VUV irradiation on the PMMA surface roughness in a nanometer range.

The initial PMMA film with a molecular mass of $8 \times 10^{4}$ and a thickness of about $0.8 \mu \mathrm{m}$ was deposited by centrifuging onto a polished $\mathrm{Si}(100)$ single crystal surface (Fig. 6a) and then nanostructured by being treated for $20 \mathrm{~s}$ in an RF $(13.56 \mathrm{MHz})$ plasma. The parameters of the surface roughness and geometry of the surface features (nanohills and nanograins) on PMMA films were studied by SPM in the atomic force microscopy (AFM) mode on a sample surface area of $1.4 \times 1.4 \mu \mathrm{m}^{2}$. The dimensions of the features were determined by the computer-aided recognition of the surface relief, which was performed using the method of feature-oriented scanning in the virtual regime [14].

It was established that the plasmachemical treatment of a PMMA film led to the formation of flat nanograins (Fig. 6b) with average lateral dimensions of about $66 \mathrm{~nm}$, an average height of about $1.8 \mathrm{~nm}$, and an average distance of about $104 \mathrm{~nm}$ between adjacent grains. The number of nanograins per unit surface area was about $122 \mu \mathrm{m}^{-2}$. The proposed nanostructure technology ensures that these results can be easily reproduced.

The formation of surface nanograins can be explained by local changes in the PMMA film density. These local changes are related to the presence of inhomogeneities in most polymers, primarily globules/grains and lamellae, as well as coils, nodes, twists, entanglements, etc. of molecular chains, which agrees with the results of other investigations $[15,16]$. In the course of

PMMA treatment in oxygen-containing plasma, the polymer is subject to significant chemical modification, including the formation of polar functional groups [17, 128], carbonate $\left(\mathrm{O}_{2} \mathrm{C}=\mathrm{O}\right)$, and carbonyl $(\mathrm{C}=\mathrm{O})$ groups. In addition, there are significant changes in the binding energies of carbon atoms in various molecular groups. The content of oxygen in the near-surface layer exhibits a significant increase during the first seconds of treatment; then the growth slows down and eventually oxygen rather slowly penetrates in depth of the material [17].

\section{Treatment of PMMA Film Surface by VUV Radiation}

Plasma-treated PMMA samples were exposed to the radiation of krypton lamps with a characteristic wavelength of $\lambda=123.6 \mathrm{~nm}$ in vacuum at a residual

The dependence that the cluster size, the rate constant $\left(K_{\text {ads }}\right)$ of blood plasma protein adsorption, and the rate constant $K_{\text {ind }}$ of induced activation of the complement system has on the effective thickness of the carbon-containing layer on LDPE surface

\begin{tabular}{|c|c|c|c|c|c|}
\hline \multirow{2}{*}{$\begin{array}{l}\text { Carbon film } \\
\text { thickness, nm }\end{array}$} & \multirow{2}{*}{$\begin{array}{l}\text { Cluster } \\
\text { size, nm }\end{array}$} & \multicolumn{2}{|c|}{$K_{\mathrm{ads}}, \mathrm{ml} /(\mathrm{mg} \mathrm{s})$} & \multicolumn{2}{|c|}{$K_{\text {ind }}$} \\
\hline & & LDPE & Vitur & LDPE & Vitur \\
\hline$<5$ & No clusters & 0.15 & 0.2 & $2.0 \pm 0.3$ & $4.5 \pm 0.3$ \\
\hline $5-12$ & $50-120$ & 0.03 & 0.03 & $0.33 \pm 0.04$ & $0.4 \pm 0.05$ \\
\hline$>12$ & Surface coverage $>80 \%$ & 0.25 & 0.1 & $4.3 \pm 0.5$ & $3.5 \pm 0.4$ \\
\hline
\end{tabular}


(a)

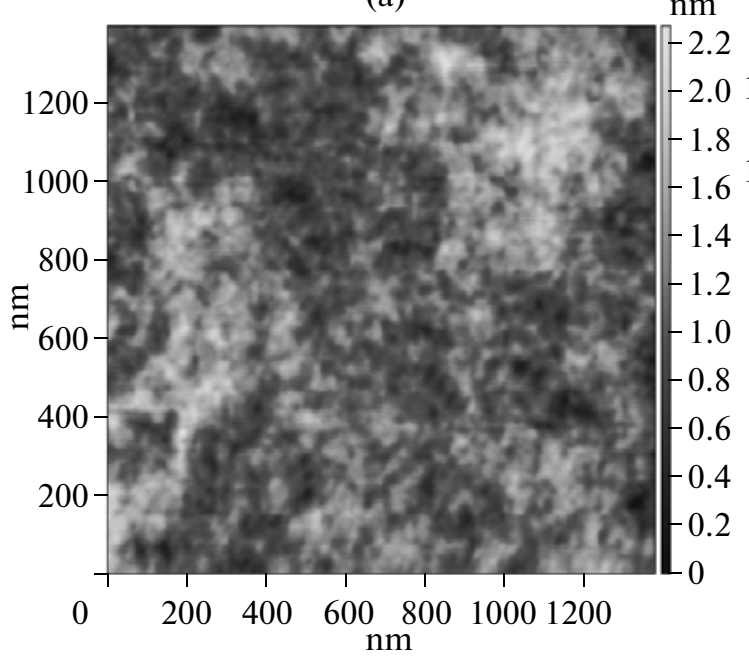

(b)

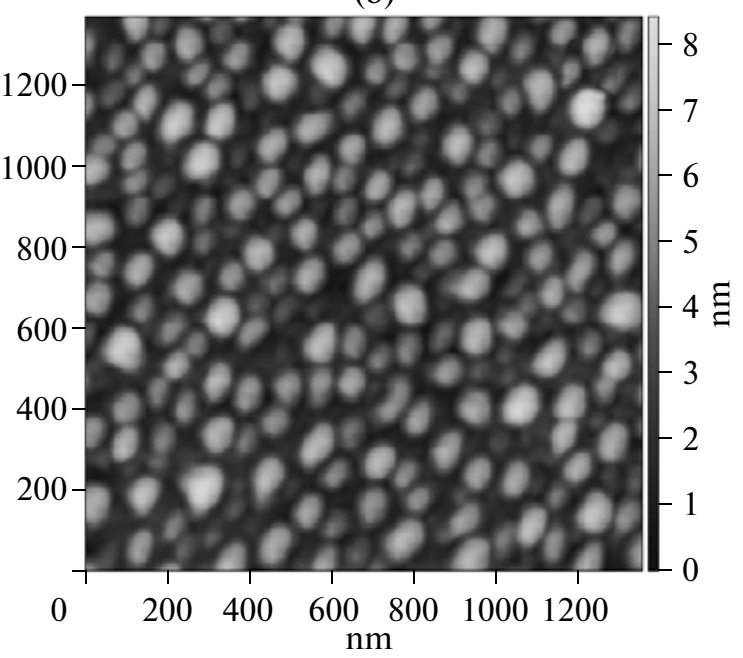

Fig. 6. AFM images of PMMA films: (a) initial film on silicon substrate; (b) nanostructured surface upon treatment in an oxygencontaining RF plasma.

pressure of 2 and $100 \mathrm{~Pa}$ for various periods of time $(0.5,1,2,5,10$, and $20 \mathrm{~min})$ on a setup described in detail elsewhere [3].

The photon energy at $\lambda=123.6$ is about $10 \mathrm{eV}$, which is large enough to excite polymer molecules and break chemical bonds such as $\mathrm{C}-\mathrm{C}, \mathrm{C}-\mathrm{H}, \mathrm{C}-\mathrm{CH}_{2}$, and $\mathrm{C}-\mathrm{O}$ [15]. Photolysis leads to the formation of low-molecular-mass gaseous products such as $\mathrm{CO}$, $\mathrm{CO}_{2}, \mathrm{H}_{2}, \mathrm{H}_{2} \mathrm{O}$, and $\mathrm{CH}_{4}$, as well as to high-molecularmass gaseous products such as methyl formate $\left(\mathrm{HCOOCH}_{3}\right)$, formaldehyde $\left(\mathrm{CH}_{2}=\mathrm{O}\right)$, methanol $\left(\mathrm{CH}_{3}-\mathrm{OH}\right)$, and methyl methacrylate $\left[\mathrm{CH}_{2}=\mathrm{C}\left(\mathrm{CH}_{3}\right)-\mathrm{COOCH}_{3}\right]$ [19]. In addition, exposure to VUV leads to the formation of intermolecular cross-links. Thus, the VUV-induced smoothing of PMMA nanorelief is due to the joint action of several processes, including the photoetching of the polymer, the redeposition of the gaseous products of photolysis, and the formation of intermolecular cross-links. The degree of smoothing (at a fixed radiation intensity) is determined primarily by the treatment duration.

An analysis of our results showed that even 2-min VUV irradiation produced clearly detectable smoothing of the roughnesses on the nanostructured PMMA surface. After 10-min exposure, the average roughness size decreased by a factor of 2.6-3; the average lateral size of nanograins was reduced by half, and their average height decreased by a factor of $15-18$. Thus, $10-$ min VUV treatment rendered the PMMA film surface practically smooth.

\section{MODIFICATION OF PMMA SURFACE BY SYNCHROTRON RADIATION}

It was also of interest to study the modification of near-surface layers of polymers by irradiation in the hard VUV $(\lambda=50-100 \mathrm{~nm})$ and soft $X$-ray $(\lambda=10-$ $50 \mathrm{~nm})$ ranges. The experiments on polymer modification in the short-wavelength spectral range were performed using a small synchrotron ring of the Kurchatov Source of Synchrotron Radiation (Moscow). However, since it is still a difficult task to separate the coherent collimated beams of various wavelengths from the entire synchrotron spectrum, the samples of PMMA films were exposed to a beam of "white" synchrotron radiation (SR). The white beam represented $\mathrm{SR}$ in the entire spectrum with $\lambda=5-400 \mathrm{~nm}$.

The irradiation of PMMA by high-energy photons of the white SR beam leads to the formation of radicals (via the Norrish type I reaction) by rupturing chemical bonds $(\mathrm{C}-\mathrm{C}, \mathrm{C}-\mathrm{H}, \mathrm{C}=\mathrm{O})$ with different energies and forming simple products such $\mathrm{H}_{2}, \mathrm{CO}, \mathrm{CO}_{2}$, and $\mathrm{CH}_{4}$. At the same time, long-wavelength photons produce the reverse effect (cross linking). As a result, exposure to white SR is accompanied by the destruction of PMMA and the subsequent cross linking of the products.

Figure 7 shows AFM images of the surface relief of PMMA films, which show evidence for self-organization and a decrease in the size of nanostructured particles. An explanation of this phenomenon can be based on the fact that polymers containing tertiary carbon atoms and possessing low enthalpy of polymerization are subject to depolymerization (thermodestruction). In addition, this is accompanied by UVradiation-induced photodestruction in the presence of $\mathrm{C}=\mathrm{O}$, which decreases the strength of bonds in the polymer backbone. Both processes lead to polymer destruction with a quantitative yield of monomers [15]. Thus the exposure of PMMA to the white SR beam leads to the appearance of structured monomers on the sample surface. 
(a)

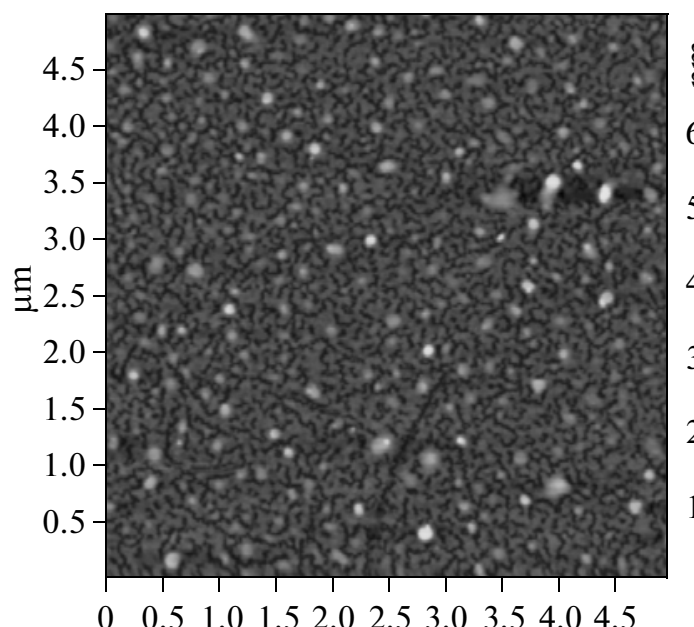

(b)

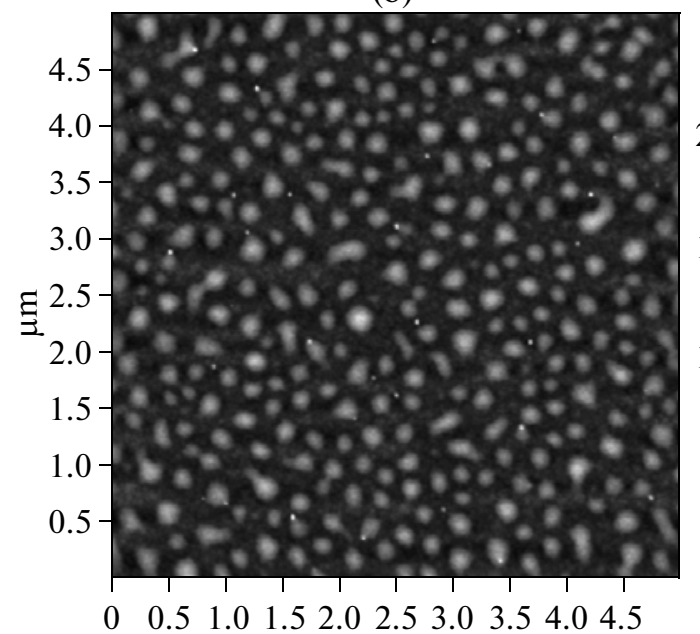

(c)

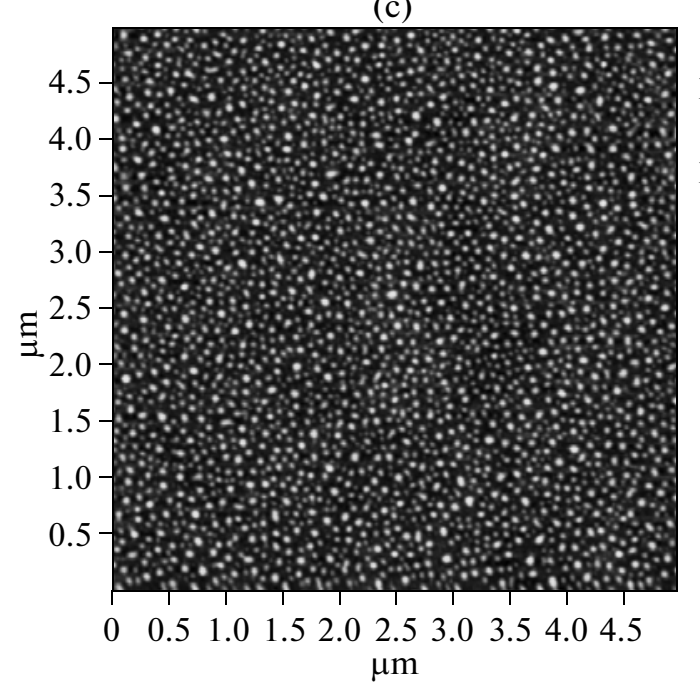

Fig. 7. AFM images of PMMA films exposed to white SR beam for (a) $1 \mathrm{~min}$, (b) $5 \mathrm{~min}$, and (c) $17 \mathrm{~min}$.

In order to check for the biocompatibility of radiation-modified surfaces, we have studied their hydrophilic-hydrophobic balance characteristics. Figure 8

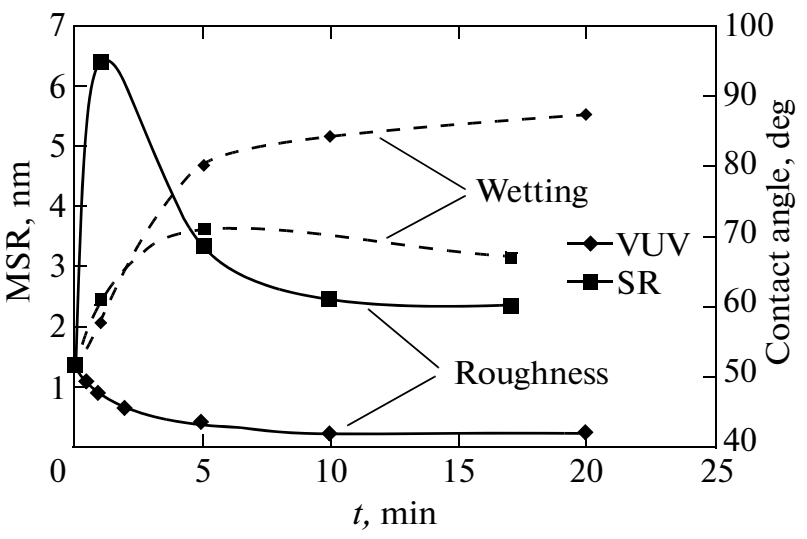

Fig. 8. Plots of the mean-square roughness (MSR) size and (wetting) contact angle on PMMA surface versus VUV and SR exposure duration $t$.

shows plots of the mean-square roughness (MSR) size and (wetting) contact angle on the PMMA surface versus VUV and SR exposure duration. As can be seen, the MSR ceases to depend on the exposure time after about 10-min irradiation and is determined by the parameters (wavelength and intensity) of the radiation source. In the case of VUV, the contact angle change is correlated with the MSR variation on the PMMA surface. Using the exposure to SR, it is possible to simultaneously modify both the surface topography (roughness) and its chemical composition by varying only the exposure time. Note that the surface wetting depends mostly on the chemical composition. These results indicate that $\mathrm{SR}$ affects the polymer surface roughness to a much greater extent than VUV radiation does.

\section{CREATION OF A BIOACTIVE SURFACE WITH ACCELERATED OSTEOINTEGRATION ABILITY BY THE ATOMIC LAYER DEPOSITION METHOD}

Most dental implants throughout the world are made of commercially available Grade 4 titanium. The most favorable type of interaction between the implant and natural bone tissue is commonly accepted to be osteointegration, which involves a complex of physiological reactions directly dependent on the surface morphology and chemical composition of the implant [20].

A developed microrelief on the titanium surface with roughness $R_{\mathrm{a}} \sim 1.4-1.7$ is conventionally formed by two methods: (i) sandblasting by corundum $\left(\mathrm{Al}_{2} \mathrm{O}_{3}\right)$ particles with dimensions ranging from several tens to several hundred of microns and (ii) etching with various appropriate acid mixtures [21]. In addition to obeying microrelief requirements, the implant surface must be wettable (hydrophilic), which is ensured by giving it a necessary chemical state [22].

It was recently demonstrated [23] that modifying the surface of titanium by anatase-one of the most 


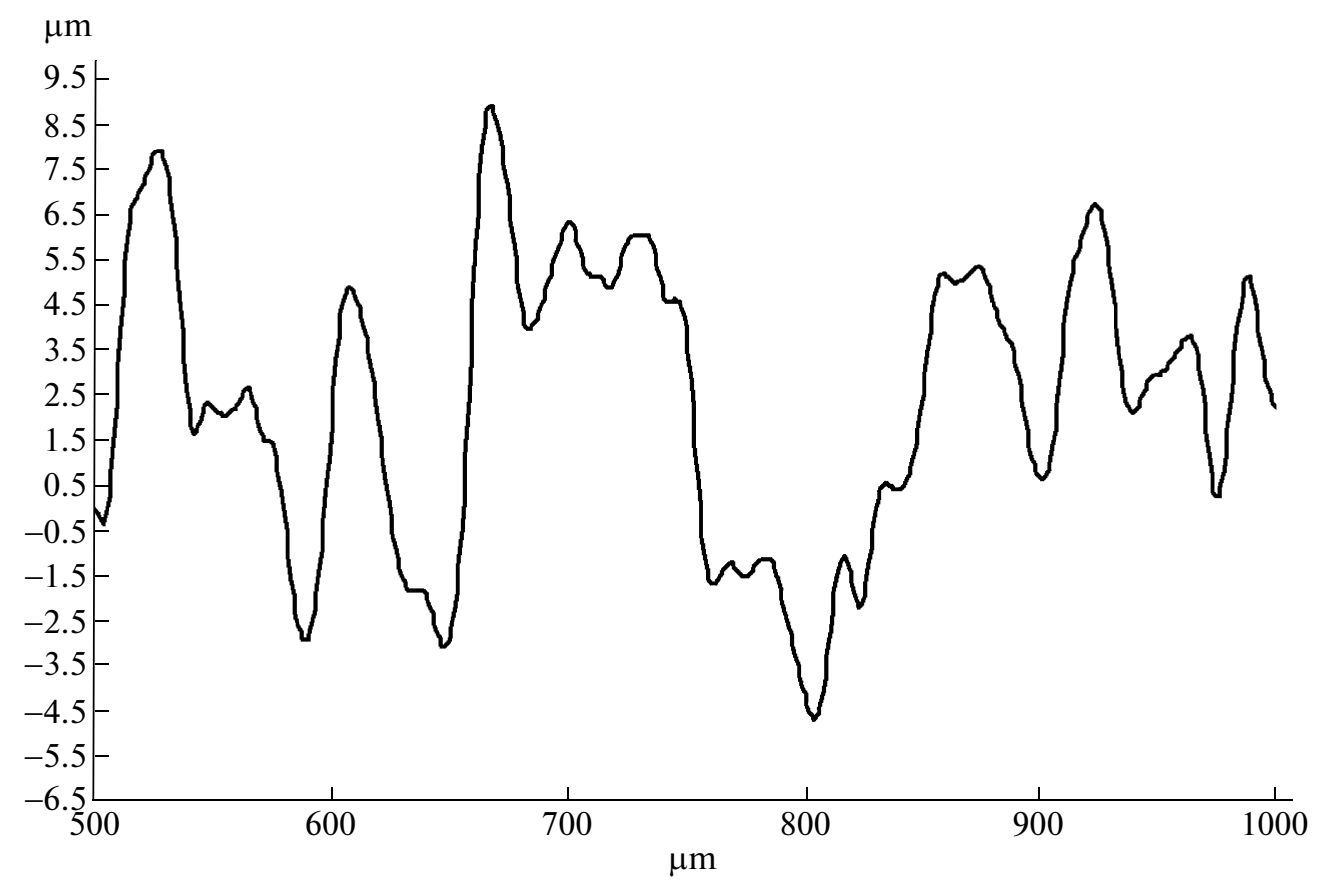

Fig. 9. Roughness profile of the titanium surface upon sand-blasting and chemical etching

widely occurring forms of titanium dioxide-leads to a significant improvement of the bioactivity of implants. In view of the above data, it was decided to create a new combined technology for the formation of biocompatible surfaces of titanium for medical applications.

\section{Developing Integrated Technology of Implant Surface Modification}

The samples of titanium were washed in an ultrasonic bath with isopropyl alcohol (special purity grade) at $50^{\circ} \mathrm{C}$; then they were rinsed in ultrahighpurity water and etched in various inorganic acids. The quantitative compositions of etchants and the treatment conditions and duration were experimentally selected with respect to two criteria: (i) obtaining a microrelief with MSR $\sim 2-3 \mu \mathrm{m}$ and (ii) ensuring a contact angle for water within $0^{\circ}-5^{\circ}$.

The topology of the etched titanium surface was characterized using an Alpha-Step prophilometer (Tencor Instruments), which showed that etched samples possess a developed relief with a maximum roughness height of $Z_{\max }=13.4 \mu \mathrm{m}$ and an average roughness of $R_{\mathrm{a}}=2.61 \mu \mathrm{m}$ (Fig. 9).

Figure 10 shows the influence that the etching time has on the surface topography and contact angle variation, which was studied using a KSV Instruments setup. The insets show SEM images of the sample surface upon etching for various periods of times. As can be seen, a minimum contact angle $\left(\sim 4^{\circ}\right)$ and most developed surface microrelief are observed upon 30-s etching.

SEM data confirmed the facts that (i) the uneven edges of surface roughnesses are smoothed by acid etching and (ii) active centers of selective etching appear on the metal surface, which lead to the formation of a fine porous structure. The surface porosity was studied by SPM on a Solver Pro M (NT-MDT Company) instrument operating in a tapping mode. The maximum probed area size was $11.5 \times 11.5 \mu \mathrm{m}$. the lateral pore dimensions were within 2-4 $\mu \mathrm{m}$ (Fig. 11).

However, the etching also led to a significant scatter of contact angles, which varied within $5^{\circ}-90^{\circ}$ in some regions. The surface chemical composition of these samples was studied by Auger electron spectroscopy (AES) (Perkin-Elmer AES instrument). The results of this analysis showed that the surface of samples exhibiting hydrophobic properties upon etching was characterized by the presence of $\mathrm{Ti}-\mathrm{C}$ bonds, which was evidence for the presence of carbon on the surface of titanium (Fig. 12). It was an increased content of hydrocarbons on the metal surface which imparted hydrophobic properties to the material surface.

Thus, the proposed method allowed a developed microrelief to be obtained on the surface of titanium. However, the formation of a carbidelike layer on the etched surface hindered a stable hydrophilic state over the entire surface of a titanium sample (Fig. 12). For this reason it was decided to stabilize the chemical composition of a titanium surface with developed microrelief using atomic layer deposition (ALD). 


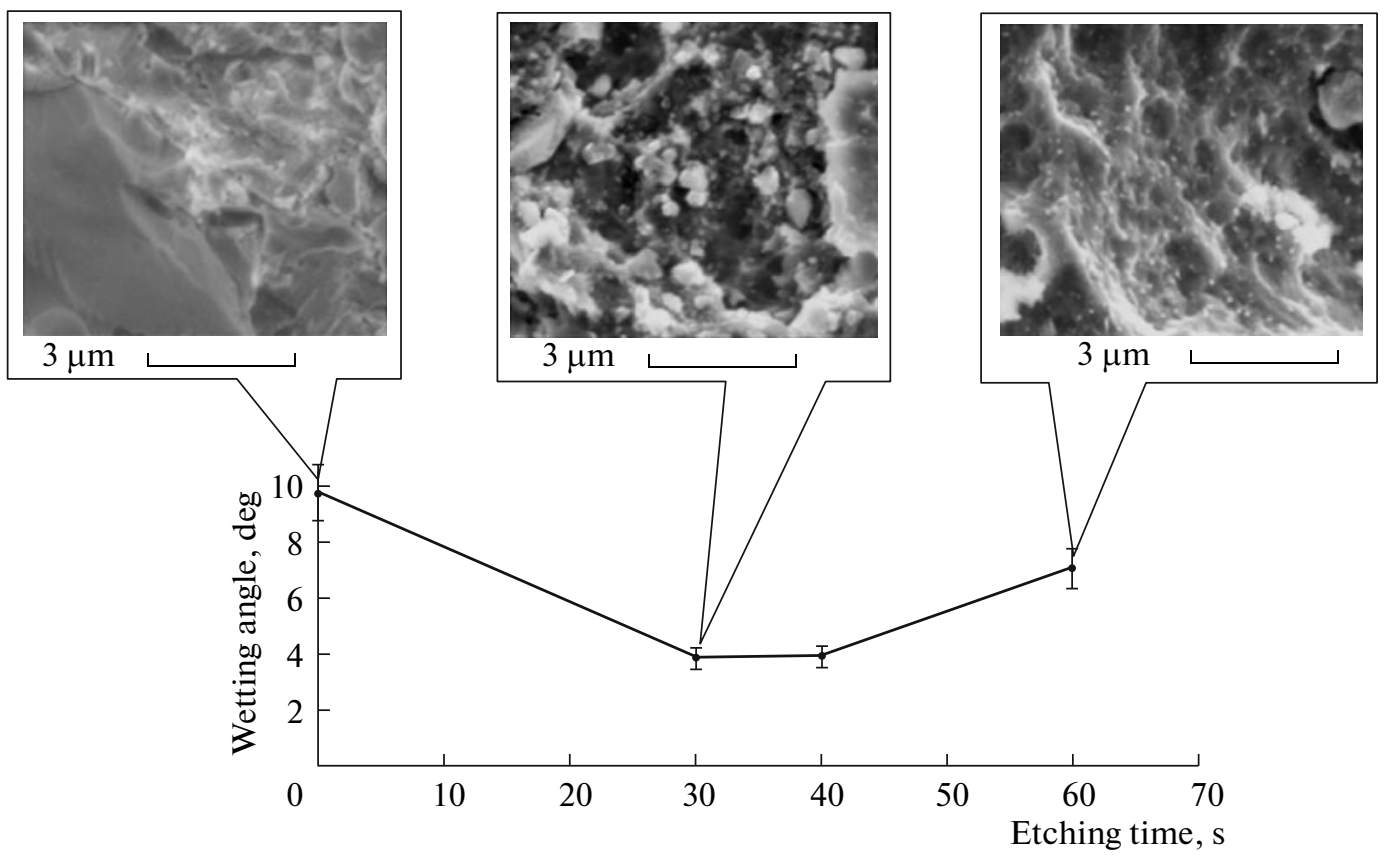

Fig. 10. Plot of the contact angle versus etching time. Insets show SEM images of the sample surface morphology at the indicated points.

(a)

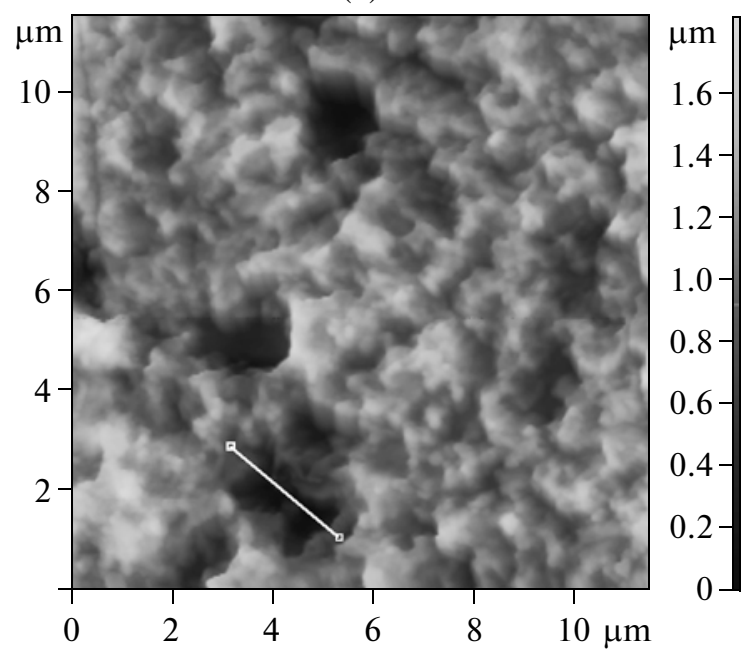

(b)

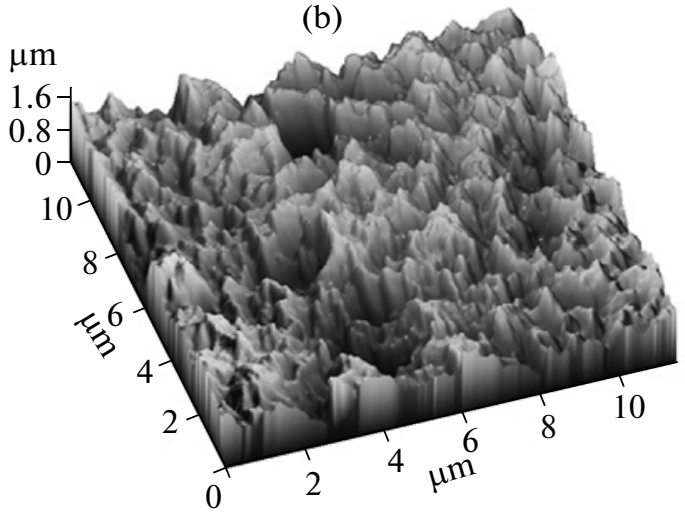

Fig. 11. (a) $2 \mathrm{D}$ and (b) $3 \mathrm{D}$ images obtained by AFM of a titanium surface etched in an acid mixture.
Why did we select the ALD method? Because it offers the following unique possibilities [24-26]:

(i) Obtaining regular, highly stoichiometric solid deposits with the desired crystal structure on a substrate at low temperatures $(300-500 \mathrm{~K})$.

(ii) Performing phase transformations bypassing high energy barriers related to nucleation, thus ensuring a conformal coating within $0.5-1.0 \mathrm{~nm}$.

One distinctive feature of the ALD technique is the pulsed supply of reactants to the substrate surface. Between these pulses, the reactor is either purged with an inert gas or evacuated. Correctly choosing the process parameters yields conditions where only a chemisorbed layer of one reactant is left on the substrate to react with another reactant that is supplied with the next pulse. This process type is sometimes referred to as self-saturation or self-control [27]. Multiply repeated reaction cycles make the layer-by-layer growth of a thin film of a preset composition possible, the total thickness of which is controlled by merely changing the number $n$ of repeated reaction cycles.

In this study we used a Sunale-R150 Model vertical ACO-type reactor (Picosum Oy) in which titanium duioxide was deposited using ethoxytitanium [97\% $\left.\mathrm{Ti}\left(\mathrm{OC}_{2} \mathrm{H}_{5}\right)_{4}\right]$ and water. Since the saturated vapor pressure of $\mathrm{Ti}\left(\mathrm{OC}_{2} \mathrm{H}_{5}\right)_{4}$ is low, it was supplied from a source heated to $150^{\circ} \mathrm{C}$. The substrate temperature during deposition was $250^{\circ} \mathrm{C}$.

An ellipsometric analysis of these titanium dioxide films showed that their refractive index was 2.48 and the standard deviation of film thickness relative to the substrate surface was within $1.8 \%$. The deposition rate 


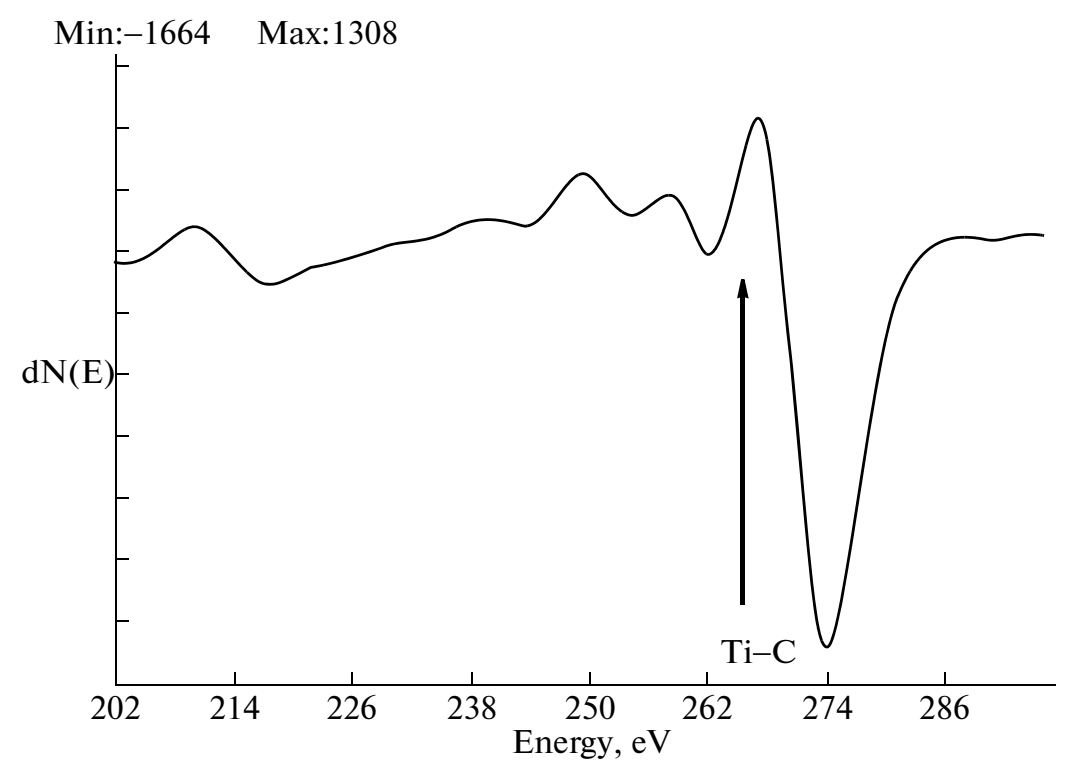

Fig. 12. AES spectrum of the acid-etched surface of titanium in the region of poor wetting (where the contact angle varied within $\left.5^{\circ}-90^{\circ}\right)$.

was $0.039 \mathrm{~nm}$ per cycle. We have prepared samples with film thicknesses of 8,24 , and $48 \mathrm{~nm}$, which were obtained using $n=200,600$, and 1200 reaction cycles, respectively.

In addition to high precision in maintaining preset film thicknesses, the ALD method also ensures unique results with respect to the uniform (conformal) coating of large developed surfaces (including those of complicated shapes), which is achieved by virtue of the fact that the reaction proceeds every time in a single layer chemisorbed on the substrate surface. We have experimentally checked for this on test structures obtained by the ion-beam processing of a silicon plate in which trapezoid-profiled grooves with a base width of $\sim 2 \mu \mathrm{m}$ and a depth of $\sim 4 \mu \mathrm{m}$ were formed and subsequently coated by titanium dioxide using the ALD method. As can be seen from Fig. 13, the $\mathrm{TiO}_{2}$ layer thickness is virtually the same over the entire surface with a complicated relief.

\section{Characterization of $\mathrm{TiO}_{2}$ Films Obtained by the ALD Method on Titanium}

$\mathrm{The}^{\mathrm{TiO}}{ }_{2}$ layers on titanium substrates were studied by Fourier transform IR spectroscopy (FTIR) (Perkin-Elmer Spectrum 100 spectrometer) and Xray diffraction (XRD) (Rigaku Ultima IY universal diffractometer), which showed that both the thickness and structure of $\mathrm{TiO}_{2}$ layers depend on the number of reaction cycles. Figure 14 shows the FTIR spectra measured in the reflection mode before (curve 1) and after (curves 2-4) $\mathrm{TiO}_{2}$ deposition by the ALD method. As can be seen, the spectra of both the titanium substrate (curve 1 ) and $\mathrm{TiO}_{2}$ layer deposited for 200 cycles (curve 2) display a broad absorption band at $700-1000 \mathrm{~cm}^{-1}$, which corresponds to amorphous titanium dioxide [9]. An increase in the number of cycles to $n>600$ leads to the appearance of a sharp peak at $870 \mathrm{~cm}^{-1}$, which corresponds to a crystalline $\mathrm{TiO}_{2}$ with an anatase structure (curves 3 and 4). According to the FTIR data, similar changes from the amorphous to polycrystalline anatase structure were observed for the films grown by the ALD on silicon substrates.

The appearance of a polycrystalline anatase structure in the layer grown by ALD with increasing number of reaction cycles was also confirmed by the XRD data (Fig. 15).

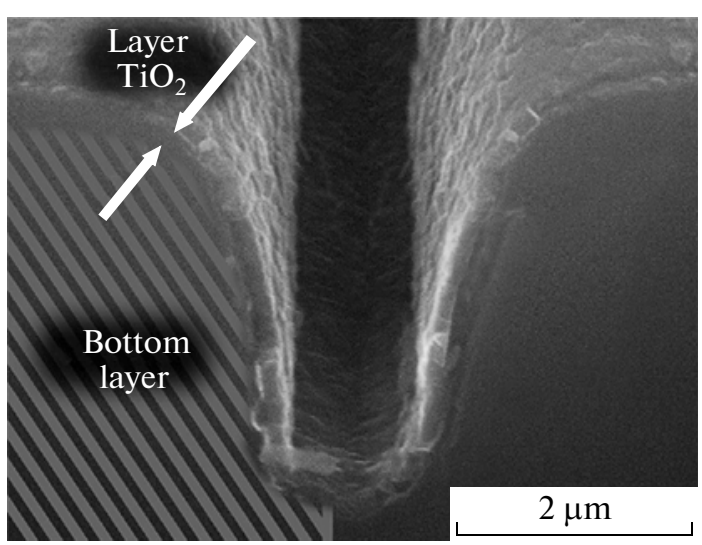

Fig. 13. SEM image of the surface of silicon with a trapezoidal groove formed using ion-beam processing followed by $\mathrm{TiO}_{2}$ deposition by the ALD method. 


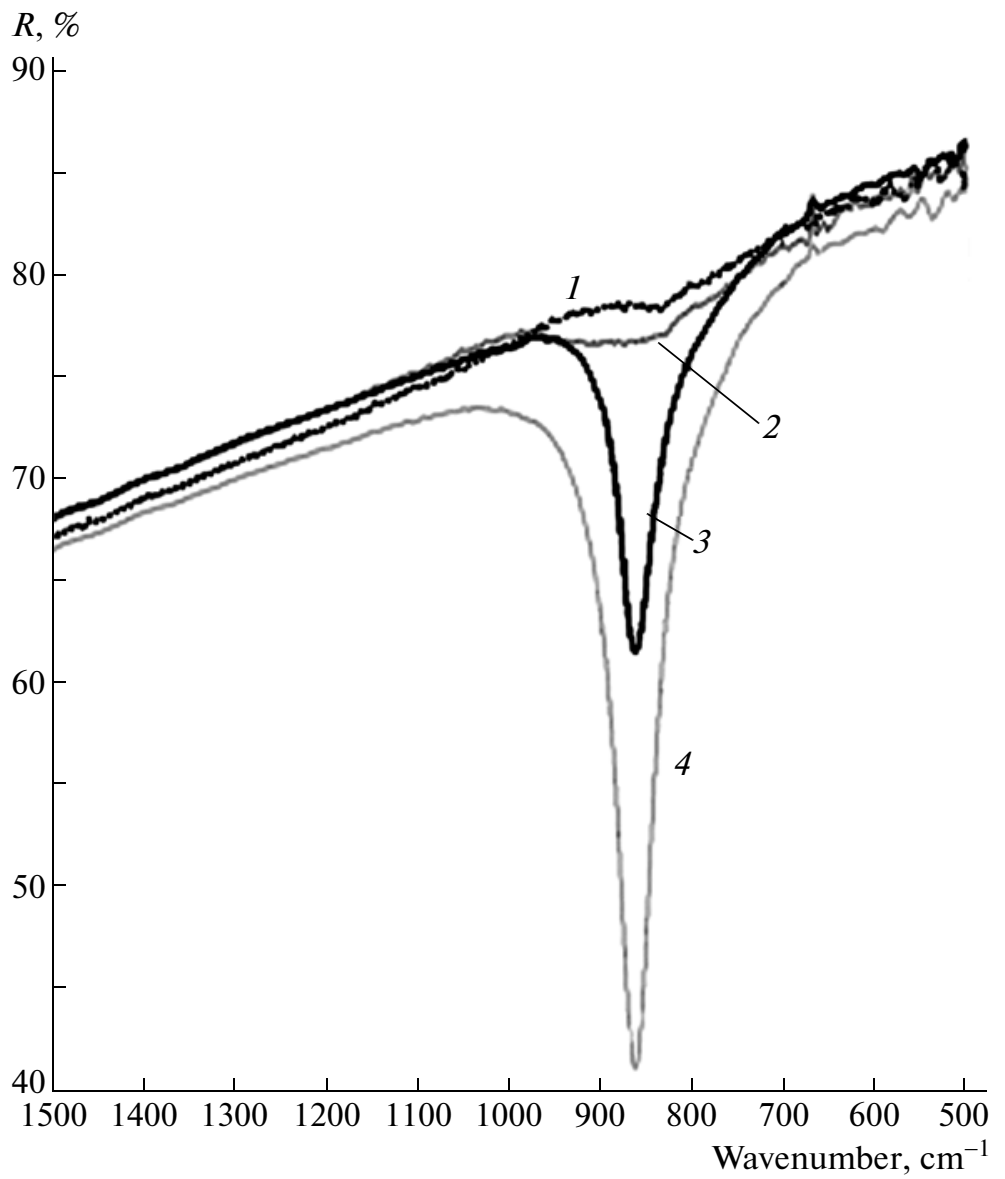

Fig. 14. FTIR spectra of $\mathrm{TiO}_{2}$ films on polished titanium substrates: (1) initial Ti substrate; (2-4) $\mathrm{TiO}_{2}$ layers grown by the ALD method using $n=200,600$, and 1200 reaction cycles, respectively.

Measurements of the wetting contact angle on the substrates with titanium dioxide coatings obtained by the ALD with $n>600$ on acid-etched titanium surfaces showed easily reproducible results with the contact angle within $0^{\circ}-5^{\circ}$.

Relative intensity, \%

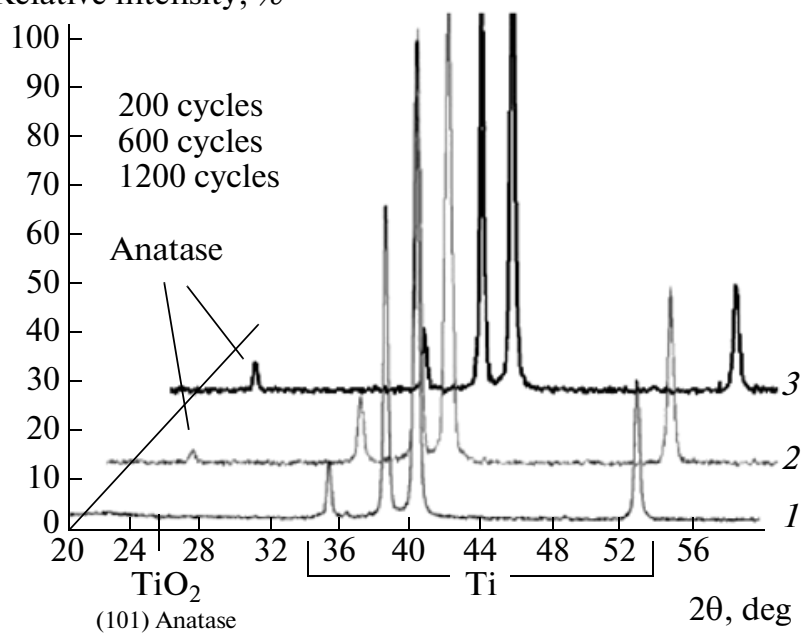

Fig. 15. XRD patterns obtained for $\mathrm{TiO}_{2}$ coating formed on titanium by the ALD for $n=$ (1) 200 , (2) 600, and (3) 1200 reaction cycles.
The biocompatibility of modified titanium samples was assessed in experiments performed according to standard method [28] with an evaluation of the ability of MC3T3-E1 osteoblast cells to proliferate, adhere, and differentiate. The ability to differentiate was eval-

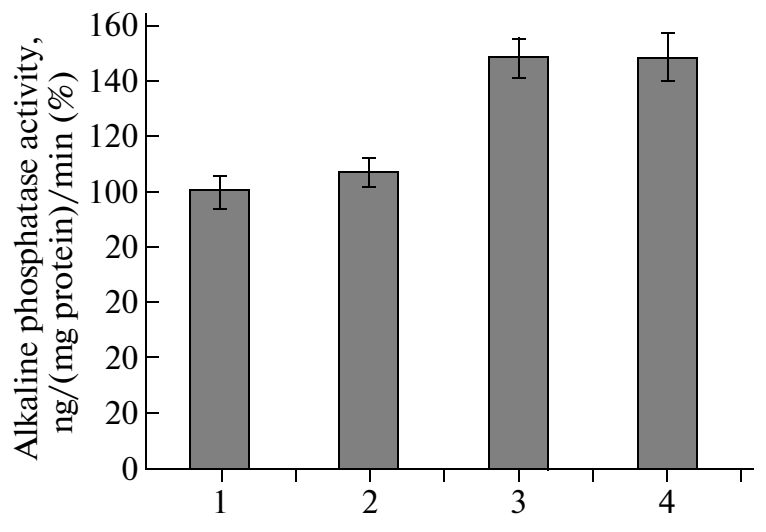

Fig. 16. Histogram of the alkaline phosphatase activity on medical titanium samples prepared by different methods: (1) initial Ti surface; (2) ALD of $\mathrm{TiO}_{2}(n=1500)$; (3) $1 \% \mathrm{HF}$ acid etching followed by the $\mathrm{ALD}_{2}$ of $\mathrm{TiO}_{2}(n=$ 1600); (4) $\mathrm{HCl} / \mathrm{H}_{2} \mathrm{SO}_{4}$ acid etching followed by the ALD of $\mathrm{TiO}_{2}(n=1600)$. 
uated by a change in the activity of alkaline phosphatase on the samples with differently prepared surfaces (Fig. 16). As can be seen, the activity of alkaline phosphatases was increased on the $\mathrm{TiO}_{2}$-coated samples where compared to the initial titanium. The best results were obtained on the samples prepared using the proposed combined technology involving the formation of a developed relief surface followed by titanium dioxide coating using the ALD method.

\section{CONCLUSIONS}

We have developed a technology for obtaining modified polymer-blood structures which involve the creation of a mosaic structure on the surface of a noncrystalline substrate in the form of carbon clusters with lateral dimensions of $10-500 \mathrm{~nm}$.

The medical and technical parameters of these structures were studied as dependent on the technological conditions of surface modification with a view to ensuring the competitive adsorption of blood plasma proteins.

We have also studied the process of smoothing nonuniformities of the surface relief on PMMA by treating polymer films in oxygen-containing RF (13.56 MHz) discharge plasma and exposing them to VUV radiation at $\lambda=123.6 \mathrm{~nm}$ and an intensity of $7 \mathrm{~mJ} /\left(\mathrm{cm}^{2} \mathrm{~s}\right)$ or white SR with $(\lambda=5-400 \mathrm{~nm})$. The nanostructured surfaces consisted of flat nanograins with an average diameter of $66 \mathrm{~nm}$, an average height of $2 \mathrm{~nm}$, and an average distance of $104 \mathrm{~nm}$ between the neighboring grains. It was established that the nanostructured PMMA surface is partly ordered. The proposed method of polymer surface smoothing by VUV radiation can be used to improve the biocompatibility of PMMA implants.

A new combined technology for processing medical Grade 4 titanium is proposed which includes the chemical etching in inorganic acids and their mixtures followed by the ALD of $\mathrm{TiO}_{2}$, which allows a modified surface with the following characteristics to be obtained:

(i) a surface relief with $R_{\mathrm{a}} \sim 3 \mu \mathrm{m}$;

(ii) hydrophilicity (contact angle $\sim 0^{\circ}-5^{\circ}$ );

(iii) chemical composition, $\mathrm{TiO}_{2}$-anatase.

It is experimentally confirmed that the ALD of $\mathrm{TiO}_{2}$ eliminates the inhibition of cell adhesion to the material surface and is a promising technology for obtaining highly biocompatible dental implants.

\section{ACKNOWLEDGMENTS}

The authors are grateful to N.Yu. Toknov for his help in preparing the manuscript and to T.M. Vasil'eva, N.A. Glushankova, E.P. Kirilenko, A.S. Mityaev, and Yu.Yu. Lebedinskii for conducting meaturements.

NANOTECHNOLOGIES IN RUSSIA Vol. 5 Nos. 9-10
This study was supported in part by the Russian Federal Agency for Science and Innovations [State Contract no. 02.435.11.20127 of September 29, 2005, within the framework of the Federal Targeted Basic Research and Technology Program "Investigations and Developments in Priority Directions of Science and Technology (2002-2006)" and State Contract no. 02.740.11.0786 as part of the Federal Targeted Program "Scientific and Pedagogical Staff for Innovative Russia (2009-2013)"], the Conmet Ltd. (Investigation Contract), and the Russian Federal Agency for Education [project no. 2.1.2/1819, Analytical Targeted Program "Development of the Scientific Potential of High Education (1009-2010)"]

\section{REFERENCES}

1. C. P. Poole, Jr. and F. J. Owens, Introduction to Nanotechnology (Wiley, New York, 2003; Tekhnosfera, Moscow, 2006).

2. A. P. Alekhin, A. G. Kirilenko, R. V. Lapshin, R. I. Romanov, and A. A. Sigarev, "Nanostructured Carbon Coatings on Polyethylene Films," Zh. Prikl. Khim. (St. Petersburg) 76 (9), 1536-1540 (2003) [Russ. J. Appl. Chem. 76 (9), 1497-1501 (2003)].

3. A. P. Alekhin, A. G. Kirilenko, and R. V. Lapshin, "Surface Morphology of Carbon Thin Films Deposited from Plasma onto Low-Density Polyethylene," Poverkhnost, No. 2, 3-9 (2004).

4. P. K. Chu, B. Y. Tang, L. P. Wang, and N. Huang, "Third-Generation Plasma Immersion Ion Implanter for Biomedical Materials and Research," Rev. Sci. Instrum. 72 (3), 1660 (2001).

5. A. A. Barybin and V. G. Sidorov, Physical and Technological Foundations of Electronics: A Textbook for Higher Educational Institutions (Lan', St. Petersburg, 2001) [in Russian].

6. A. P. Alekhin et al., "The Method for Modifying the Surface of a Polymer," RF Patent No. 2325192 (May 27, 2008).

7. V. I. Sevast'yanov, Biocompatibility (VNIIGS Testing Centre, Moscow, 1999) [in Russian].

8. V. I. Sevast'yanov, I. A. Titushkin, S. L. Vasin, I. B. Rozanova, and A. P. Alekhin, "Influence of the Structural and Energy-Related Properties of Carbon Coatings on the Adhesion of Human Thrombocyte," Perspekt. Mater., No. 5, 24 (1999).

9. A. P. Alekhin, A. I. Vrublevskii, A. M. Markeev, R. I. Romanov, and V. N. Nevolin, "On the Structure and Properties of Amorphous Carbon-Containing Films Produced by Magnetically Active MicrowavePlasma Deposition," Poverkhnost, No. 10, 47 (1996).

10. M. Tamba, K. Kawamura, K. Okazaki, and H. Amemiya, "Formation of Diamond-Like Carbon by a Pure Carbon Arc under High Vacuum," Jpn. J. Appl. Phys. 40, 1064-1066 (2001).

11. E. A. Nemets, O. S. Polukhina, V. A. Egorova, A. V. Kuznetsov, V. N. Vasilets, and V. I. Sevast'yanov, "Modification of Polymeric Biomaterials under Vacuum Ultraviolet Radiation," Vestn. Transplantol. Iskusstvennykh Organov, No. 3, 116 (2002). 
12. V. N. Vasilets, A. V. Kusnetsov, and V. I. Sevastianov, "Vacuum Ultraviolet Treatment of Polyethylene to Change Surface Properties and Characteristics of Protein Adsorption," J. Biomed. Mater. Res., Part A 69A, 428-435 (2004).

13. A. N. Ponomarev, V. N. Vasilets, and R. V. Tal'roze, "Plasma-Chemical Modification of Polymers," Khim. Fiz., No. 21 (4) (2002).

14. R. V. Lapshin, A. P. Alekhin, A. G. Kirilenko, S. L. Odintsov, and V. A. Krotkov, "Vacuum Ultraviolet Smoothing of Nanometer-Scale Asperities of Poly(methyl methacrylate) Surface," Poverkhnost, No. 1, 35 (2010) [J. Surf. Invest. 4 (1), 1 (2010)].

15. N. Vourdas, A. Tserepi, and E. Gogolides, "Nanotextured Super-Hydrophobic Transparent Poly(methyl methacrylate) Surfaces Using High-Density Plasma Processing," Nanotechnology 18 (12), article 125304 (7 pages) (2007).

16. S. Yoshida, T. Ono, and M. Esashi, "Conductive Polymer Patterned Media Fabricated by Diblock Copolymer Lithography for Scanning Multiprobe Data Storage," Nanotechnology 19 (47), article 475302, (9 pages) (2008).

17. J. Chai, F. Lu, B. Li, and D. Y. Kwok, "Wettability Interpretation of Oxygen Plasma Modified Poly(methyl methacrylate)," Langmuir 20 (25), 10919-10927 (2004).

18. H. Lim, Y. Lee, S. Han, J. Cho, and K.-J. Kim, "Surface Treatment and Characterization of PMMA, PHEMA, and PHPMA," J. Vac. Sci. Technol., A 19 (4), 1490-1496 (2001).

19. N. Sulca, A. Lungu, Sorina Alexandra Garea, and H. Iovu, "Monitoring the Synthesis of New Polymer Nanocomposites Based on Different Polyhedral Oligo- meric Silsesquioxanes Using Raman Spectroscopy," J. Raman Spectrosc. 40 (11), 1641-1644 (2009).

20. A. P. Alekhin, A. M. Markeev, D. V. Tetyukhin, E. N. Kozlov, and M. A. Stepanova, "Influence of Physicochemical Properties of the Surface of Titanium Implants and the Methods Used for Their Modification on the Osteointegration Characteristics," Klin. Stomatol., No. 3, 3 (2009).

21. M. Lampin, C. Warocquier, C. Legris, M. Degrange, and M. F. Sigot-Luizard, "Correlation between Substratum Roughness and Wettability, Cell Adhesion, and Cell Migration,” J. Biomed. Mater. Res. 36, 99 (1997).

22. G. Zhao, Z. Schwartz, M. Wieland, F. Rupp, J. GeisGerstorfer, D. L. Cochran, and B. D. Boyan, "HighSurface Energy Enhances Cell Response to Titanium Substrate Microstructure," J. Biomed. Mater. Res., Part A 74A, 49 (2005).

23. J. Heinrichs, T. Jarmar, M. Rooth, and H. Enqvist, "In Vitro Bioactivity of Atomic Layer Deposited Titanium Dioxide on Titanium and Silicon Substrates," Key Eng. Mater. 361-363, 689 (2008).

24. V. B. Aleskovskii, Stoichiometry and Synthesis of Solid Compounds (Nauka, Leningrad, 1976) [in Russian].

25. A. A. Malygin, "Molecular Layering Nanotechnology," Ross. Nanotekhnol. 2, 87 (2007).

26. G. V. Lisichkin, Chemistry of Grafted Surface Compounds (Fizmatlit, Moscow, 2003) [in Russian].

27. R. I. Puurunen, "Surface Chemistry of Atomic Layer Deposition: A Case of Study for the Trimethylaluminum/Water Process,” J. Appl. Phys. 97, 121 (2005).

28. Hae-Won Kim, Hyoun-Ee Kim, and Jonathan C. Knowles, "Fluor-Hydroxyapatite Sol-Gel Coating on Titanium Substrate for Hard Tissue Implants," Biomaterials 25 (17), 3351-3358 (2004). 